NASA Technical Memorandum 86334

NASA-TM-86334 19850006479

\title{
THE AERODYNAMICS OF SOME GUIDED PROJECTILES
}

M. LEROY SPEARMAN
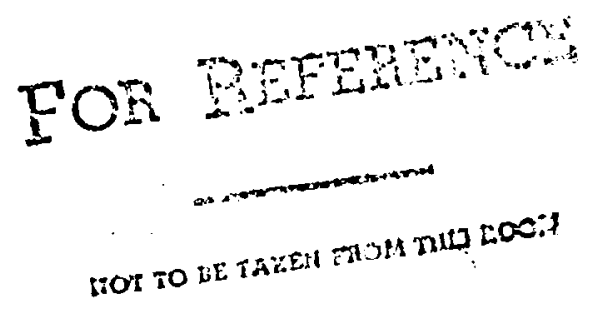

DECEMBER 1984

\section{N/Sก \\ National Aeronautics and \\ Space Administration \\ Langley Research Center \\ Hampton, Virginia 23665}

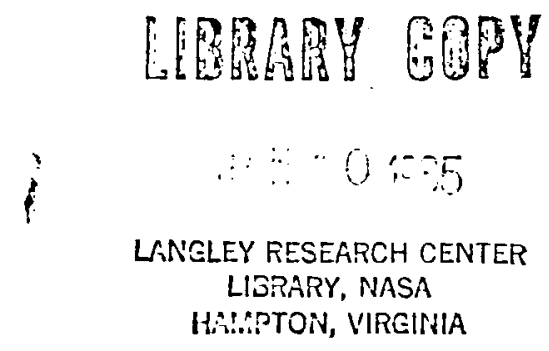


31176005190104 


\section{SUMMARY}

A review has been made of some selected body-of-revolution projectile shapes to which various components were added for the purpose of providing lift, stability, and control. The purpose of the component additions was to provide means for altering a basic projectile ballistic path to achieve greater accuracy, extend the range, improve evasion, and so on. The results indicated that the addition of wings, tails, or a flare to a body could each provide a measure of stability. Wings were particularly effective in providing lift. Al1-moving wings, aft tails, or close-coupled flaps all provided control to varing degrees. Thus it was concluded that the additon of components to a projectile-type body could easily provide a means for varying the flight trajectory to enhance the accuracy, extend or vary range, improve evastueness, increase target selectability, and so on.

\section{INTRODUCT LON}

Ballistic projectiles of various types have been in use for many years--indeed, for centuries. In recent years, increased attention has been given to what is referred to as guided projectiles. The intent of the guided projectile is, of course, to provide greater control of the projectile flight path in order to improve the accuracy, extend the range, and increase target selectability. In addition, greater control of the flight path could relieve some of the constraints imposed by the launch conditions.

\section{SYMBOLS}

$\begin{array}{ll}C_{D} & \text { drag coefficient } \\ C_{D, 0} & \text { drag coefficient at zero lift } \\ C_{i} & \text { rolling-moment coefficlent } \\ C_{L} & \text { lift coefficient } \\ C_{m} & \text { pitching-moment coefficient } \\ C_{n} & \text { yawing-moment coefficient } \\ C_{{ }_{B}} & \text { effective dihedral parameter } \\ C_{n_{B}} & \text { directional stability parameter } \\ C_{m} & \text { longitudinal stability parameter } \\ C_{l_{\delta}} & \text { roll control effectiveness }\end{array}$




$\begin{array}{ll}\mathrm{C}_{\delta} & \text { lift control effectiveness } \\ \mathrm{C}_{\delta} & \text { pitch control effectiveness } \\ \mathrm{C}_{\delta} & \text { yaw control effectiveness } \\ \mathrm{L} / \mathrm{D} & \text { lift-to-drag ratio } \\ \mathrm{X} & \text { longltudinal distance from body nose } \\ \mathrm{l} & \text { body length } \\ \text { d } & \text { diameter of body cylinder } \\ \text { a.C. } & \text { aerodynamic center } \\ \text { c.g. } & \text { center of gravity or moment reference point } \\ \alpha & \text { angle of attack, deg } \\ \delta & \text { control deflection, deg } \\ \text { C } & \text { roll angle, deg } \\ \text { B } & \text { body } \\ W & \end{array}$

\section{DISCUSSION}

Concepts

Body With Wings and With Flare.- The characteristics for a body with alterations that included wings, a flared skirt, close-coupled flap controls, and an all-moving forward wing or canard control have been extracted from references 1 to 4 . The concepts (Fig. 1) had a basic body with a length/diameter ratio, 1/d, of 10 formed by an equal length forebody and afterbody. The body had a slightly rounded nose followed by a straight tapered section which faired into an ogive which, in turn, faired into a cylinder. Alterations were: (1) 85-degree swept cruciform wings with close-coupled rectangular flap controls; and (2) a 10-degree flared skirt and 70-degree swept canard-type controls. All fin surfaces were flat plates with rounded leading edges and flat tips and trailing edges.

Some of the longitudinal characteristics for these concepts as a function of Mach number are presented in Figure 2 with the c.g. at 0.51 and $\alpha=0^{0}$. The 
addition of the wings or the flare to the basic body provide positive stability. When the canard control is added to the flared body, however, a destabilizing tendency occurs at the lower Mach numbers. Above about $M=4$, the stability of the winged body beglns to decrease whereas the stabllity level for the flared bodycanard progressively increases to the maximum test Mach number of 6.8 . The decrease in stability for the winged configuration results from a loss in lift from the wing. The increase in stability for the flared configuration results from an increase in effectiveness of the flare and, in part, from a loss in lift of the canard which is located slightly forward of the c.g. At all Mach numbers, the drag penalty is considerably greater for the flare than for the wings. The pitch effectiveness for both the wing flap and the canard progressively decrease with $M$ and both are about zero at $M=6.8$. The lift effectiveness for the flap also decreases, reaching zero at $M=6.8$, at which point the winged configuration would no longer be controllable with the flap. The lift effectiveness of the canard is maintained throughout the Mach number range, however, hence, even at $M=6.8$, some controllability is available through translation (direct 1 ift).

Some trim values of lift-to-drag ratio for the winged and flared concepts are shown in Figure 3 for several Mach numbers and as a function of stability level. The values for the body-wing configuration are somewhat more sensitive to variations in c.g. and $M$ than those for the body-flare-canard. Not unexpectedly, the winged configuration is more effective at the lowest Mach number and the $f$ lared configuration tends to become more efficlent at the higher Mach numbers. In any event, these data indicate that level flight is attainable so that range extension is possible--the extent being dependent on several other factors including projectile weight, flight altitude, and thrust availability.

Body with Wing and Tail Controls.- The characteristics for a body with alterations that included wing controls, tail controls, and combined wing and tail controls have been extracted from reference 5. The concepts (Fig. 4) had a basic body with a length-diameter ratio of 10.17 composed of a pointed ogive over the forward third of the body that faired into a cylinder. Additions to the body included aft, low-aspect ratio, rectangular cruciform tails, and 70-degree clipped delta cruciform wings. The wings and tails were flat plates with rounded leading edges and flat tips and trailing edges. Both the wings and the tails could be deflected for control.

The effects of the various components on the longitudinal aerodynamics at $M=1.9$ are shown in Figure 5 for a reference c.g. of 0.7 l. For this c.g., the addition of the tall to the body provides a substantial stabilizing increment in pitching-moment that is reduced somewhat by the further addition of the wing. The magnitude of these pitching moment changes are, of course, a function of the c.g. location. The tail and the wing add increments of lift with that for the wing beling about twice that for the tail for this configuration. The lift increment due to the tail is noticeably reduced by the presence of the wing. The addition of the tatis or the wings increased the minimum drag and reduced the drag due to 1 ift as would be expected. These effects are reflected in the lift-to-drag ratios.

The variations of $C_{D, o}$ with $M$ (Fig. 6) indicate higher drag increments due to the tail than due to the wing, probably because of the difference in sweep angle. The variations of a.c. location with M (Fig. 6) indicate that a relatively farforward c.g. location would be required to provide static longitudinal stability with the exception of the BT configuration below about $M=3$. Center of gravity locations on the order of 40- to 45-percent 1 should not be difficult to achleve for a projectile, however. 
The increments in pitching-moment for various control combinations are shown in Figure 7. While the magnitudes will be a function of c.g. location, the trend effects will be essentially the same. These results show that pitch rotation is produced by either tail or wing deflection. The tail is slightly more effective when the wing is removed because of the interference effect of the wing-flow field at the tail. The wing control is more effective when the tail is on because of an induced download on the tail. The largest rotational moment is produced when both the wing and the tail are deflected to produce pitch.

The control effectiveness parameters, $\mathrm{C}_{\mathrm{m}_{\mathrm{S}}}$ and $\mathrm{C}_{\mathrm{I}_{\mathrm{f}}}$ (Fig. 8) Indicate that pitch rotation and lift increments are produced over the test Mach number range. Hence, alterations to the flight path, including level flight, are possible.

Wing-Body With Tail Controls.- The characteristics for a wing-body with tail controls have been extracted from test results that are, as yet, unpublished. The concept (Fig. 9) had a body with a bi-conic forebody, a cylindrical center section, and a short boattailed afterbody with an overall length-to-diameter ratio of 8.7 . The cruciform wings were 63-degree clipped-delta planforms with circular arc sections. The all-moving in-line cruciform tails had a trapezoldal planform and hexagonal sections.

The effects of various components on the longitudinal characteristics at $M=1.9$ are shown in Figure 10. The tails add only a small stabilizing increment, being relatively small in size. The wing, being aft of the c.g., provides a large stabilizing increment and the complete configuration, BWT, for the conditions shown, displays positive stability with reasonably linear characteristics up to at least $\alpha=20^{\circ}$. The increment in lift provided by the wing is fairly large while that of the tail is fairly sma11. Small increments in minimum drag are caused by the addition of the wings and tails but the drag due to lift is reduced and these effects are reflected in the lift-to-drag ratios with a maximum value of about 3 occurring for the BWT at a $C_{\text {f }}$ of about 2. The longitudinal control characteristics for these conditions (Fig. 11) indicate good control effectiveness and no apparent difficulty in trimming at the lift for inaximum L/D.

The longitudinal summary (Fig. 12) indicates only a small rearward shift in aerodynamic center location with increasing Mach number, varying from about

$0.61 \mathrm{l}$ at $M=1.5$ to about $0.54 \mathrm{l}$ at $M=4.6$. Hence for any $\mathrm{c} . \mathrm{g}$. forward of 54 percent $l$, static longitudinal stability could be maintained. Modest decreases in $C_{D}, 0$ and $C_{L}$ are indicated with increasing $M$. The drag increment due to the wing and tail are shown by the dashed line at the lower Mach numbers. There were no measureable differences in $\mathrm{C}_{\mathrm{L}}, \mathrm{C}_{\mathrm{D}, 0}$, or a.c. location for roll attitudes of
0 and 45 degrees.

The directional-1ateral stability for this concept (Fig. 13) at $M=1.9$ and c.g. $=0.57 \mathrm{l}$ indicate that directional stablifty was maintained to at least $\alpha=20^{0}$ for $\phi=45^{0}$ and to $\alpha=16^{0}$ for $\phi=0^{\circ}$. The effective dihedral was zero for both $\phi=0^{0}$ and $45^{\circ}$ up to $\alpha=16^{\circ}$. Thus, for these conditions, satisfactory directional and lateral stability is maintained to well above the angle required for maximum $\mathrm{L} / \mathrm{D}$. Other test data indicates that the directional stability becomes about neutral above about $M=3$ for the c.g. of 0.571 . The level of directional stability could be increased for high Mach numbers with an appropriate forward movement of the c.g. 
The induced yaw and roll for various values of $\phi$ are shown in Figure 14 for $M=1.9$. There are no significant departures until beyond $\alpha=10^{\circ}$.

A control summary (Fig. 15) indicates that pitch, roll, and yaw effectiveness is maintained over the test Mach number range for both $\phi=0^{0}$ to $45^{\circ}$. For these data, two tail surfaces were deflected for pitch and yaw at $\phi=0^{0}$, and four tail surfaces were deflected for $\phi=45^{\circ}$. Four surfaces were deflected for roll at both $\phi=0^{\circ}$ and $45^{\circ}$. The indications are that there should be no difficulty in maintaining control for this concept.

\section{Alternate Trajectories}

The results for each of the projectile-type concepts presented indicate that the possibility for trajectory alterations exists. The possibilities are almost endless because of the multitude of variables that could be consldered. Some examples of trajectory alterations are illustrated in Figure 16. These vary from modest changes to a ballistic path near impact in order to improve accuracy, to high altitude level-flight segments for extending range, to an early push-over for a low altitude approach.

A cursory study was made for the third concept in order to get a better understanding for the aerodynamic implications on the possible performance. The ability to alter the impact point appears to be no problem. For changes involving segments of level flight, however, many perturbations could be examined. For a 16-inch diameter body and an arbitrary weight of about 1,000 pounds, for example, it was found that level flight at maximum $L / D$ and $\phi=0^{0}$ could be maintained at 20,000 feet for $M=1.5,30,000$ feet for $M=1.9,50,000$ feet for $M=3$, and 70,000 feet for $M=4.6$. The dynamic pressure for these conditions would be about 1,500 pounds per square foot (psf). For a sea-level target approach, it was found that the projectile could malntain its weight in level flight at $M=1.5$ with a dynamic pressure of about $3,300 \mathrm{psf}$ and $\mathrm{L} / \mathrm{D}$ of about 0.7 . For $M=1.9$, such an approach could be made with a dynamic pressure of about $5000 \mathrm{psf}$ and $\mathrm{L} / \mathrm{D}$ of about 0.4. The instantaneous normal. acceleration for these sea-level approaches would be about $10 \mathrm{~g}^{\prime} \mathrm{s}$ at $M=1.5$ and about $15 \mathrm{~g}^{\prime} \mathrm{s}$ at $M=1.9$.

\section{CONCLUDING REMARKS}

It has been the purpose of this paper to examine some projectile-type concepts employing various aerodynamic components intended to provide lift, stability, and control with a view toward achieving means for altering the flight trajectory. The trajectory changes could be used to improve the accuracy, alter the impact point, or vary the approach to the target.

Some concluding observations are:

o The addition of wings, tails, or a flare to a body could each provide a measure of stability.

o Wings, in particular, were effective in providing lift.

o All-moving wings, aft tails, or close-coupled flaps could all provide control to varying degrees. 
o An illustrative concept with a wing-body and tail controls indicated that altering the flight trajectory for improved accuracy should be no problem, and that level flight segments could be sustained from sea level to at least 70,000 feet for a 16-inch diameter projectile weighing about 1,000 pounds.

\section{REFEFENCES}

1. Turner, Kenneth L.; and Applch, W. H., Jr.: Investigation of the Static Stability Characteristics of Five Hypersonlc Misstle Configurations at Mach Numbers From 2.29 to 4.65. NACA RM L58D04, 1958.

2. Robinson, Ross B.; and Bernot, Peter T.: Aerodynamic Characteristics at a Mach Number of 6.8 of Two Hypersonic Missile Configurations, One With Low-AspectRatio Cruciform Fins and Trailing-Edge Flaps and One With a Flared Afterbody and Al1-Movable Controls. NACA RM L58D24, 1958.

3. Spearman, M. Leroy; and Robinson, Ross $B_{\bullet}$ : Longitudinal Stability and Control Characteristics at Mach Numbers of 2.01, 4.65, and 6.8 of Two Hypersonic Missile Configurations, One Having Low-Aspect-Ratio Cruciform Wings With Trailing-Edge Flaps and one Having a Flared Afterbody and All-Movable Controls. NASA TM X-46, 1959.

4. Church, James D.; and Kirkland, Ida M.: Static Aerodynamic Characterlstics of Several Hypersonic Missile-and-Control Configurations at a Mach Number of 4.65. NASA TM $X-187,1960$.

5. Graves, Ernald B.: Supersonic Aerodynamic Characteristics of a Low-AspectRatio Missile Model with Wing and Tail Controls and with Tails in Line and Interdigitated. NASA TM X-2531, 1972. 


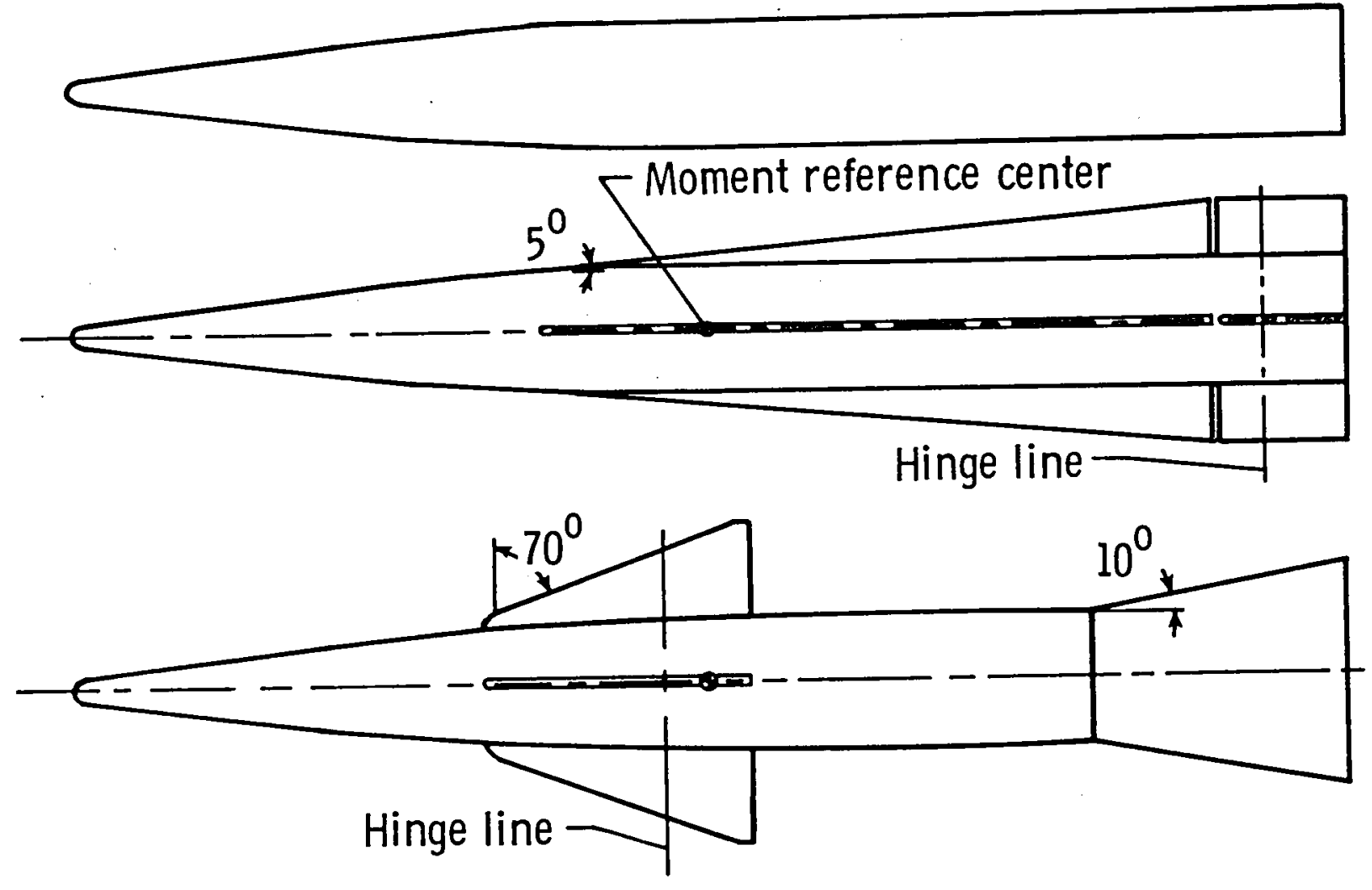

Figure 1.- Body with wings and with flare, $l / d=10$. 

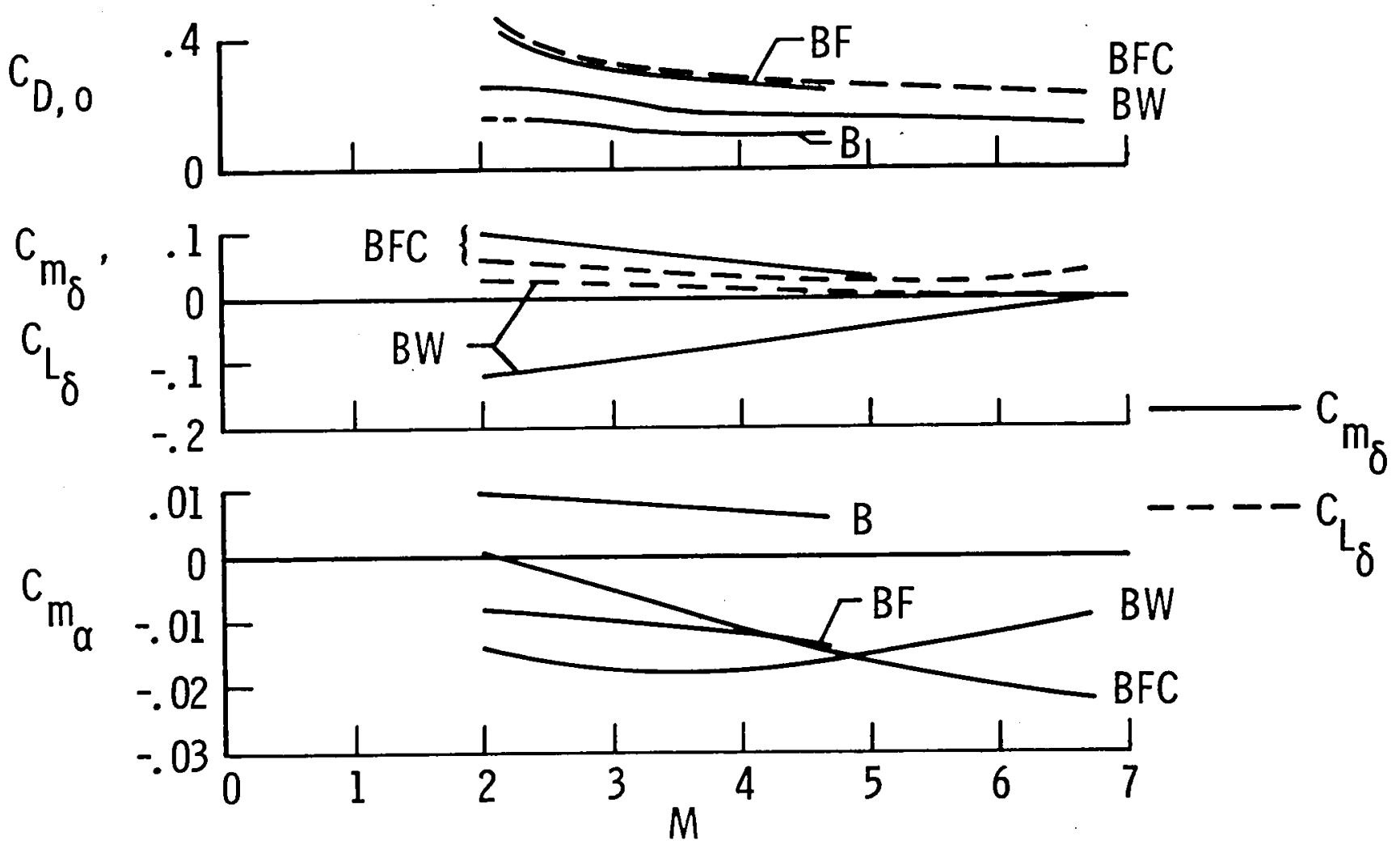

Figure 2.- Longitudinal characteristics, body with wings and with flare, c.g. $=0.501, \alpha=0^{\circ}$. 

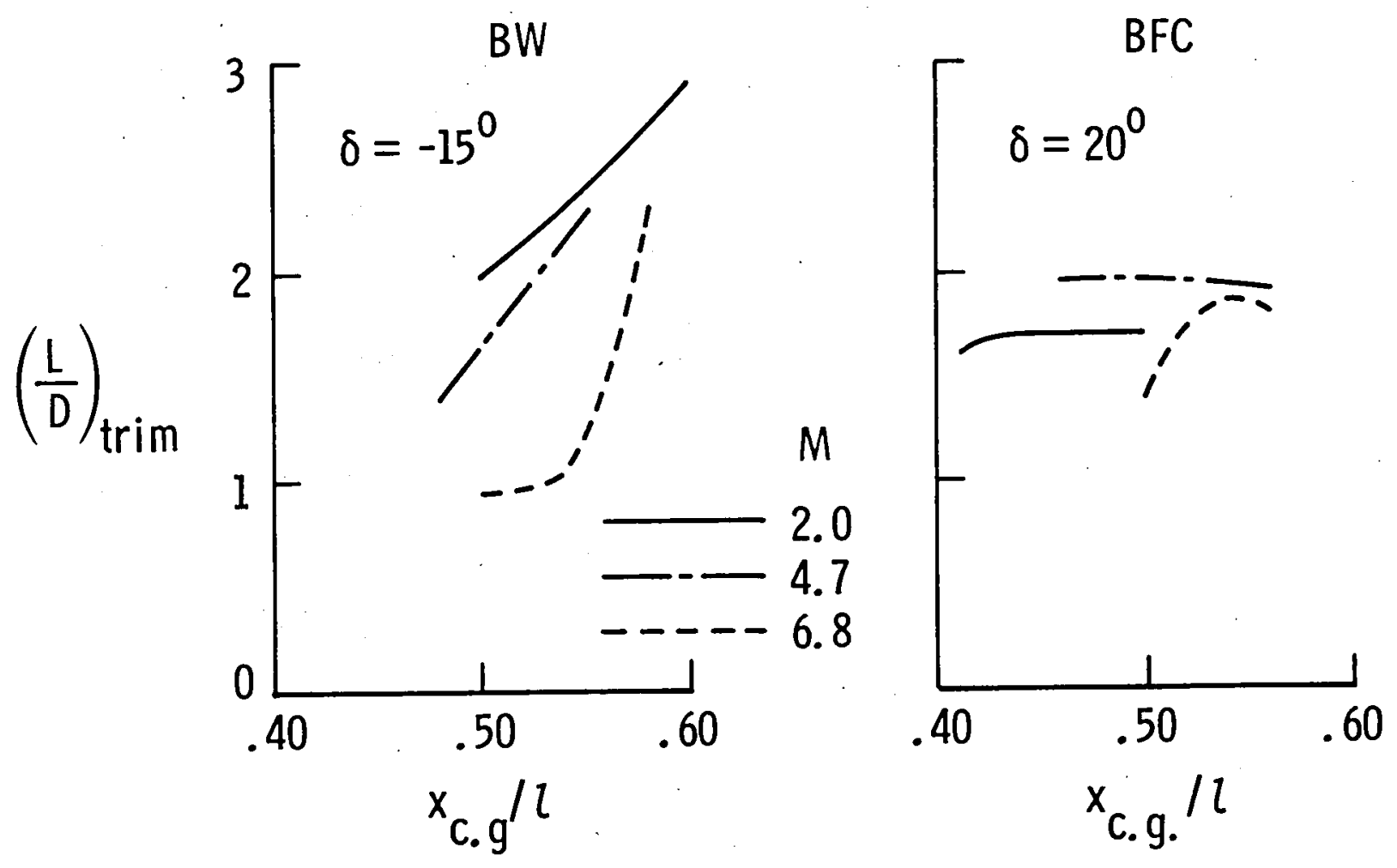

Figure 3.- Trimmed lift-drag ratios, body with wings and with flare. 


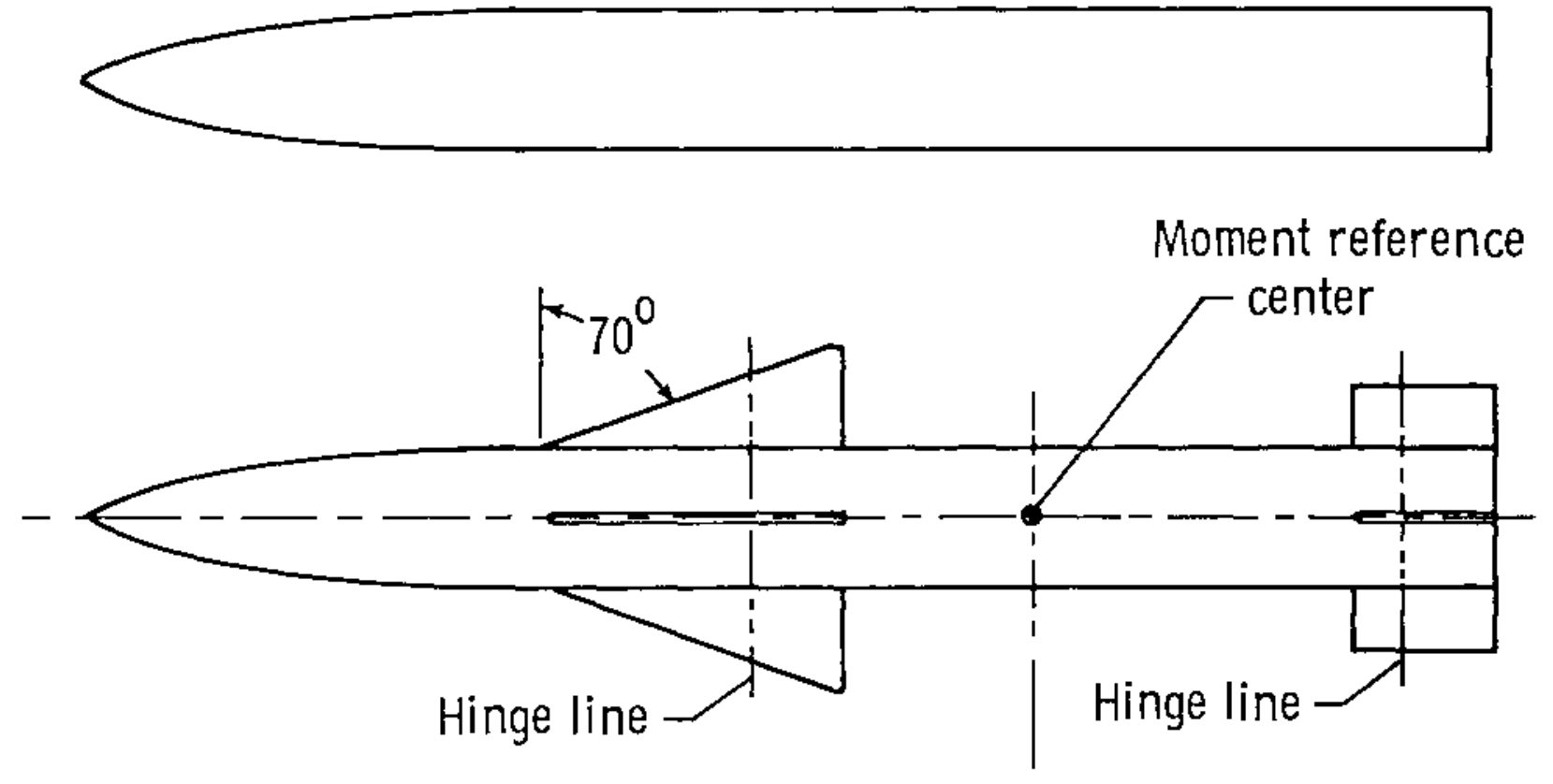

Figure 4.- Body with wing and tail controls, $1 / d=10.17$. 

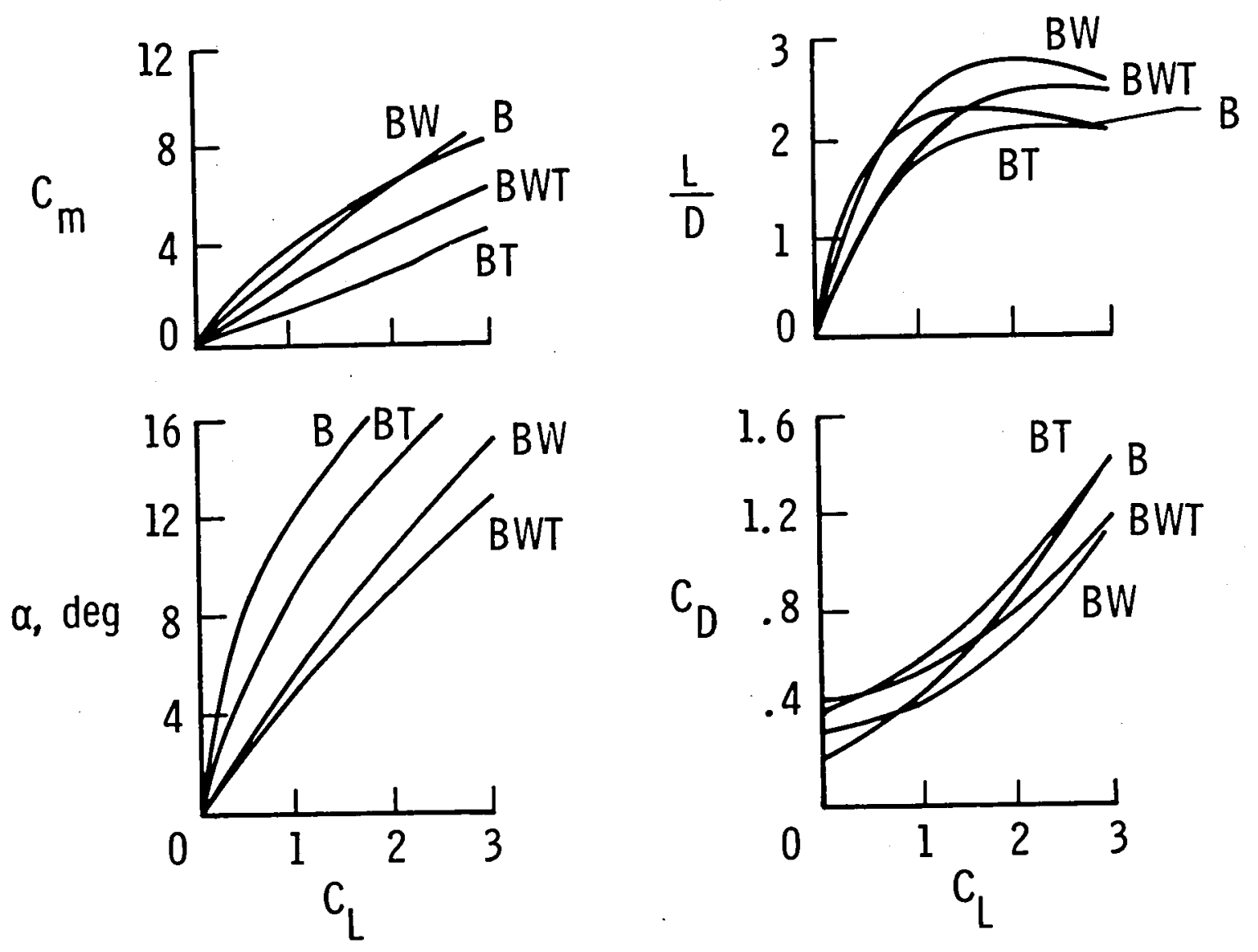

Figure 5.- Effect of components, body with wing and tail controls, $M=1.9$, c.g. $=0.70_{1}$. 

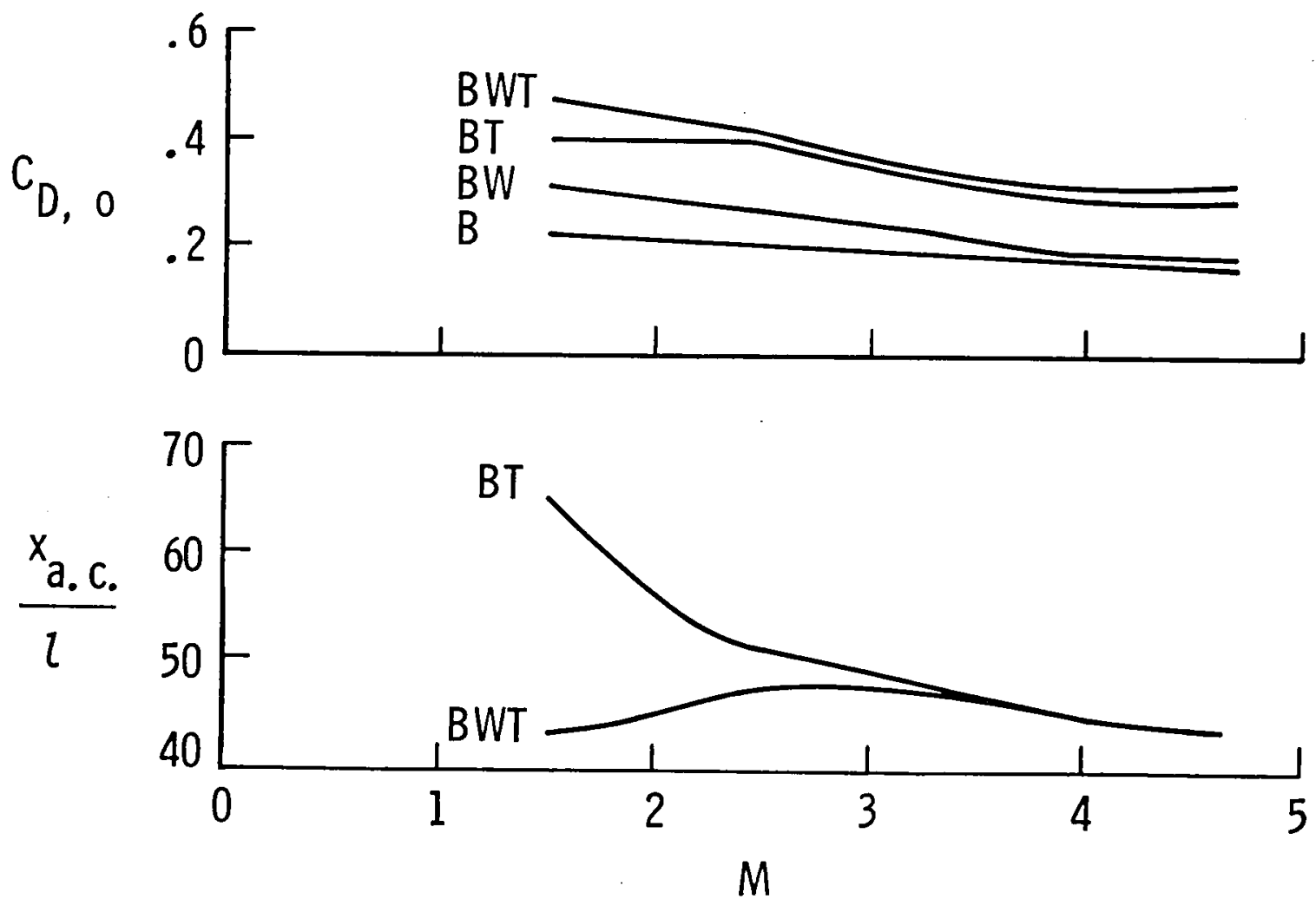

Figure 6.- Longitudinal characteristics, body with wing and tail controls. 


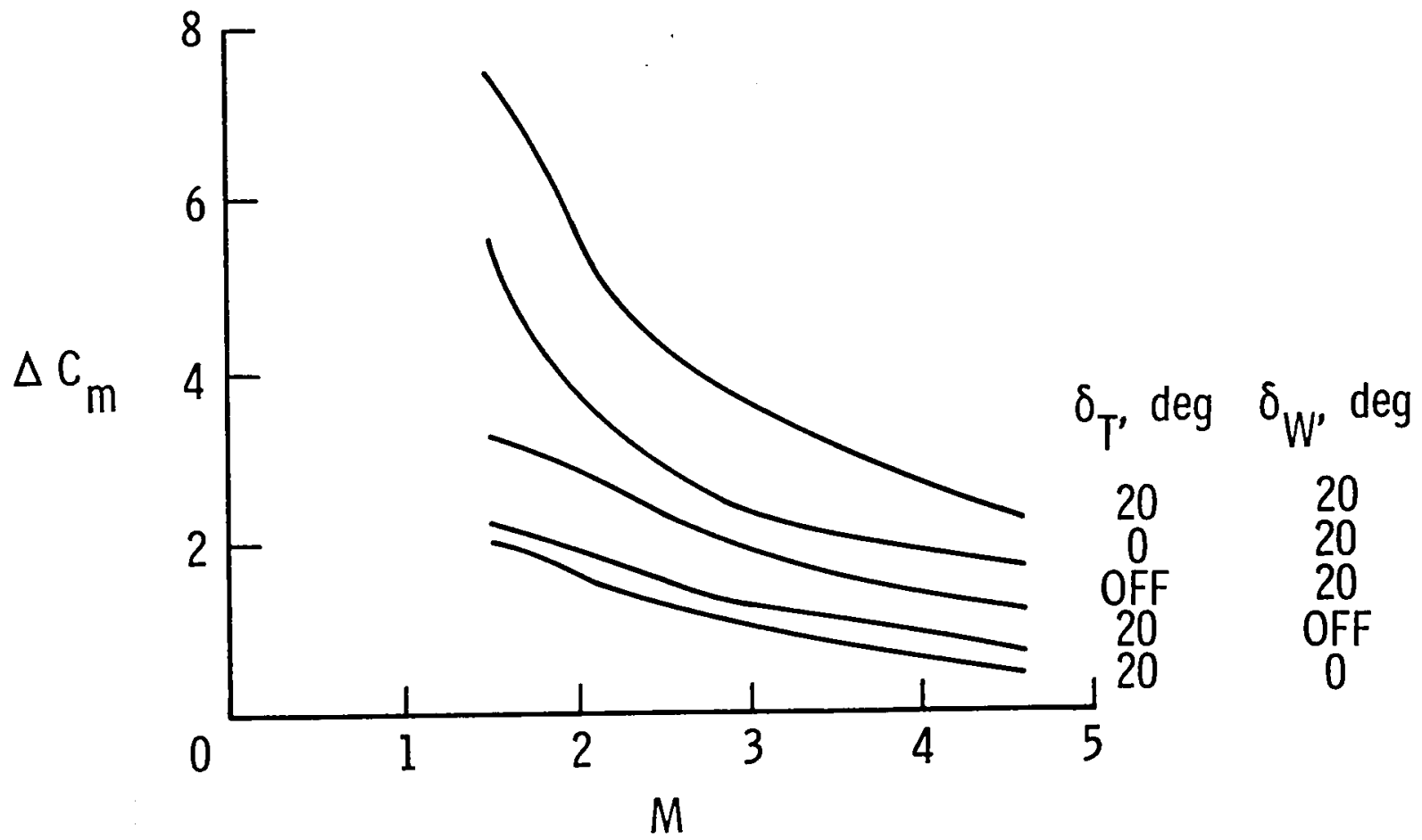

Figure 7.- Pitch control effectiveness, body with wing and tail controls, $\alpha=0^{\circ}$, c.g. $=0.70_{l}$. 

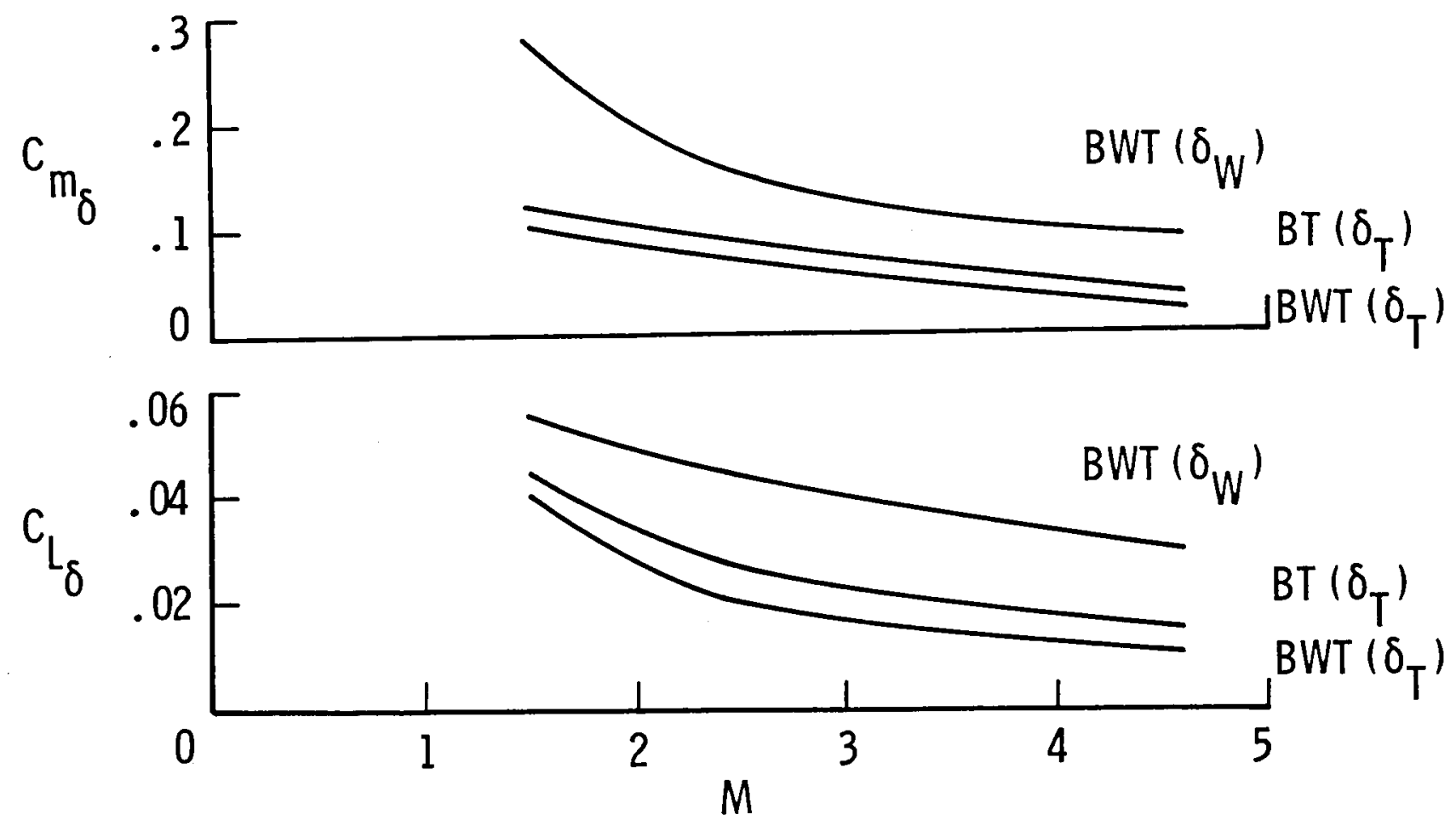

Figure 8.- Control effectiveness parameters, body with wing and tail controls, $\alpha=0^{\circ}, \mathrm{c.g} .=0.70_{1}$. 

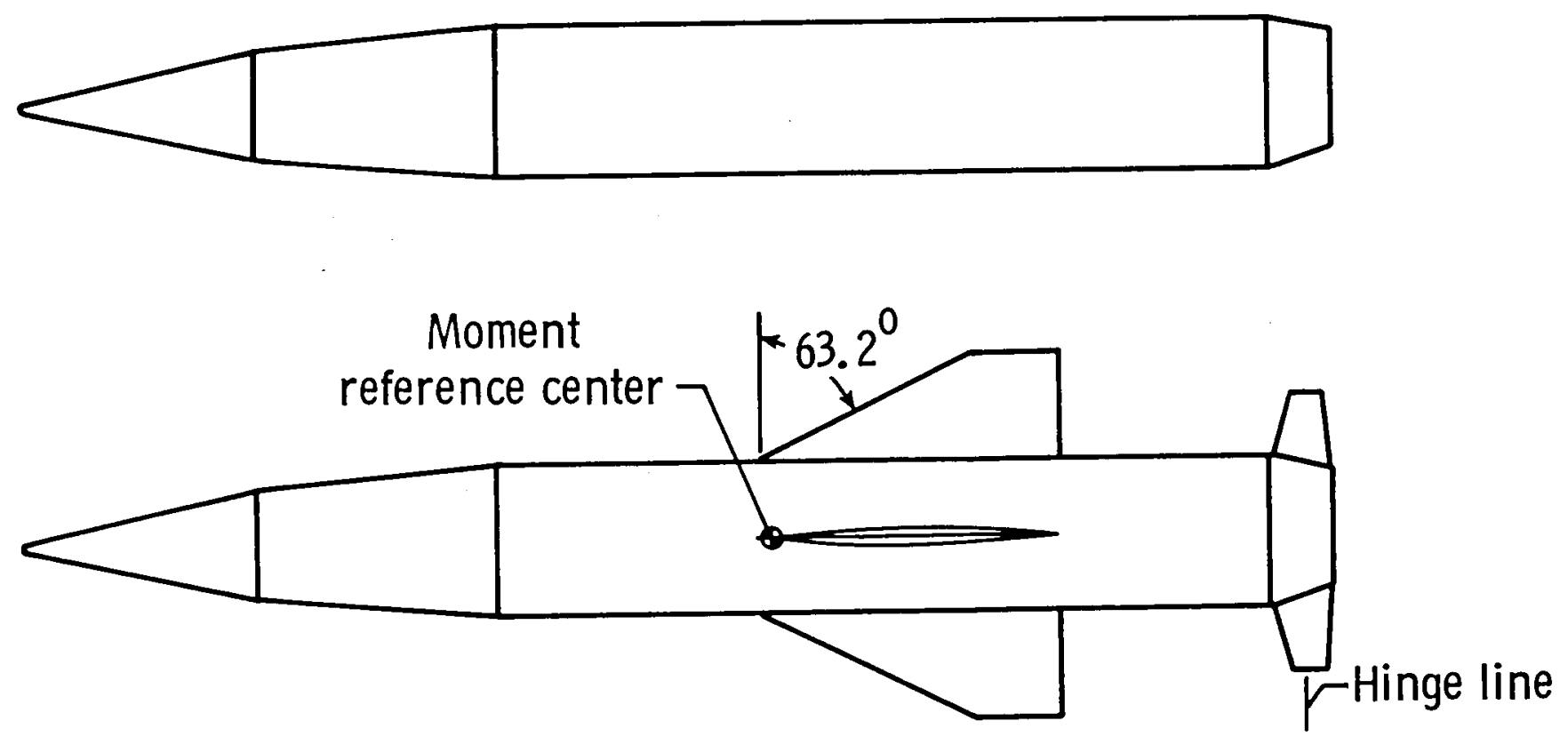

Figure 9.- Wing-body with tail control, $1 / d=8.7$. 

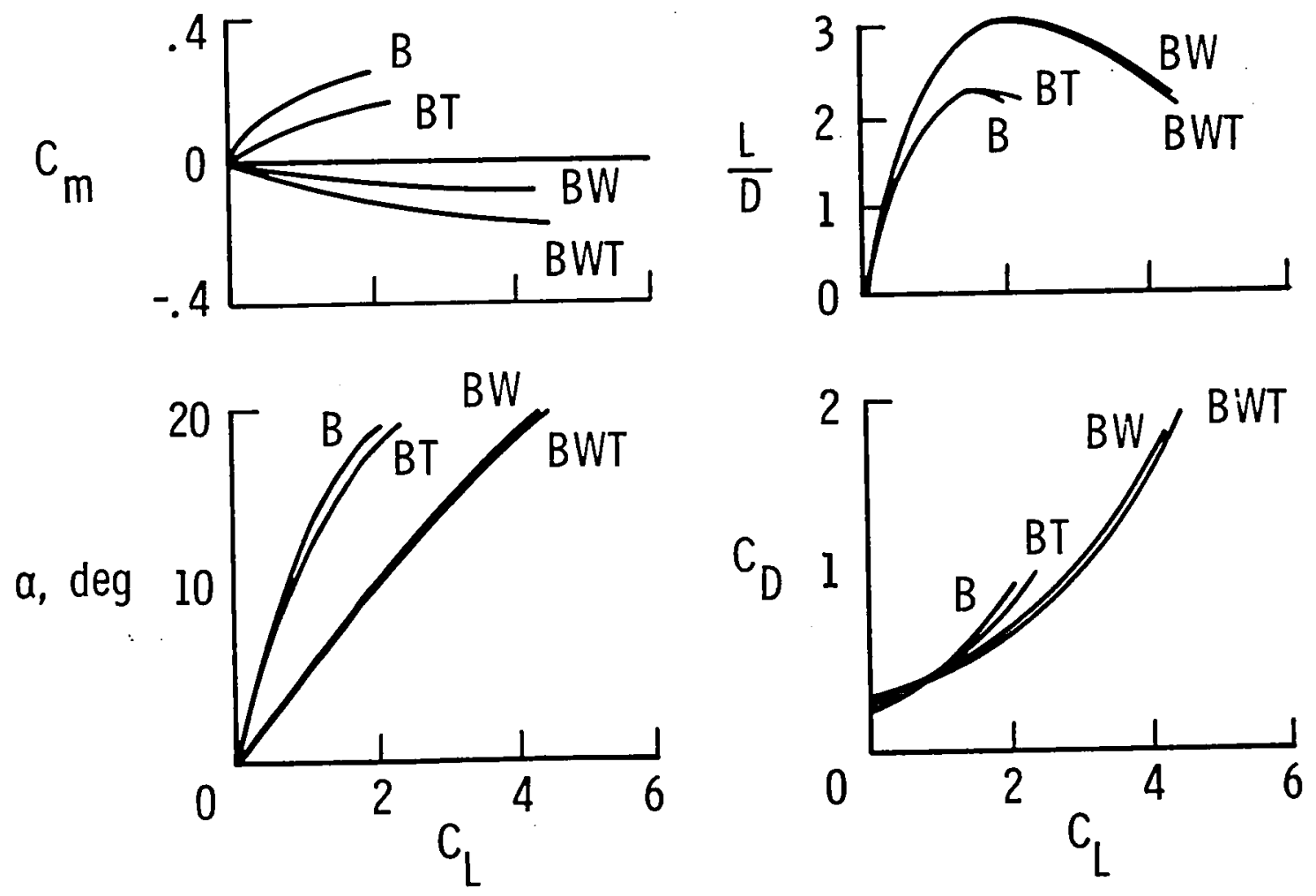

Figure 10.- Effect of components, wing-body with tail control, $M=1.9, \phi=0^{\circ}, \delta=0^{\circ}, \mathrm{C} . \mathrm{g} .=0.57 \mathrm{l}$. 

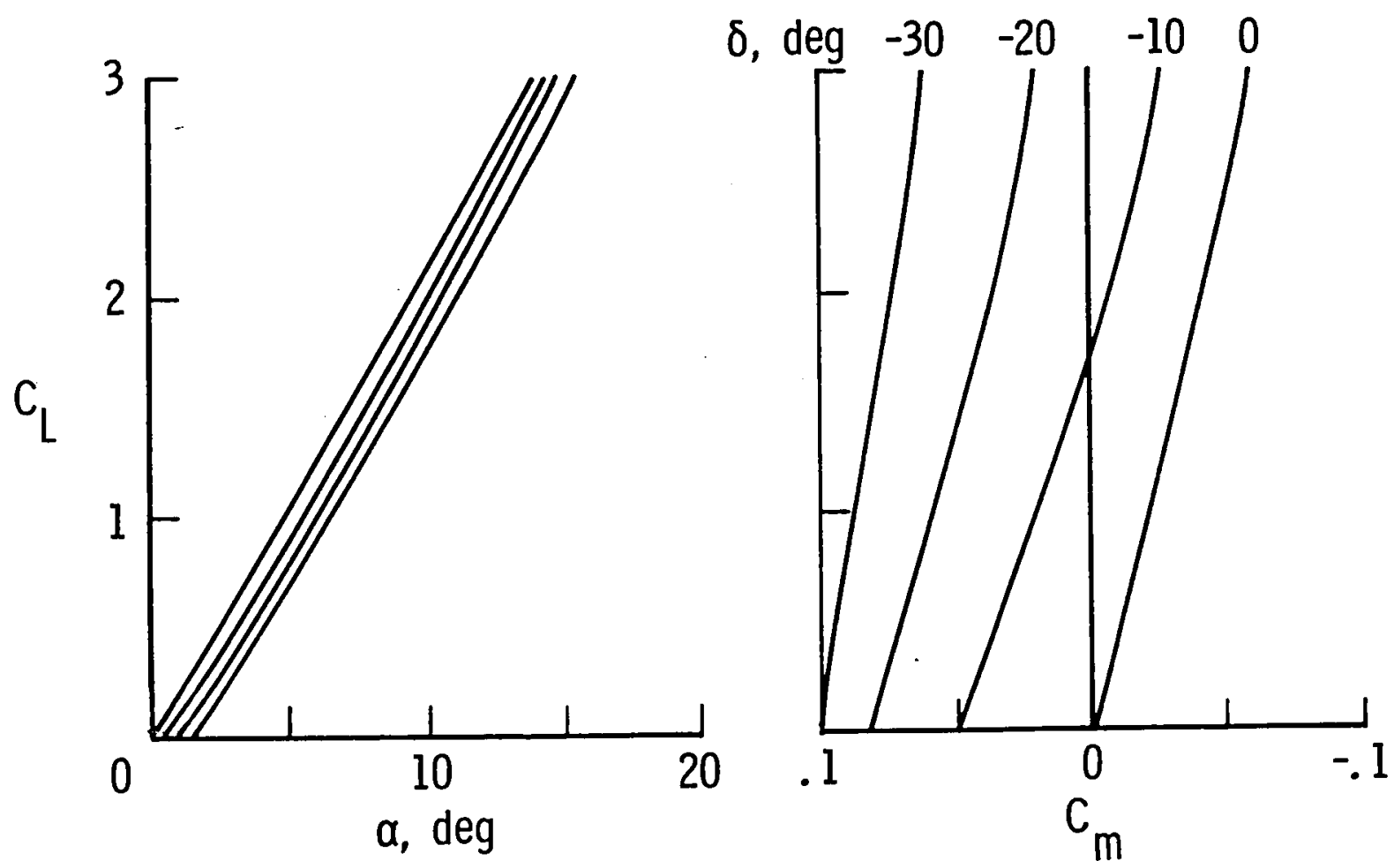

Figure 11.- Longitudinal control characteristics, wing-body with tail control, $M=1.9, \phi=0^{\circ}, \mathrm{c} . \mathrm{g} \cdot=0.57_{\mathrm{l}}$. 


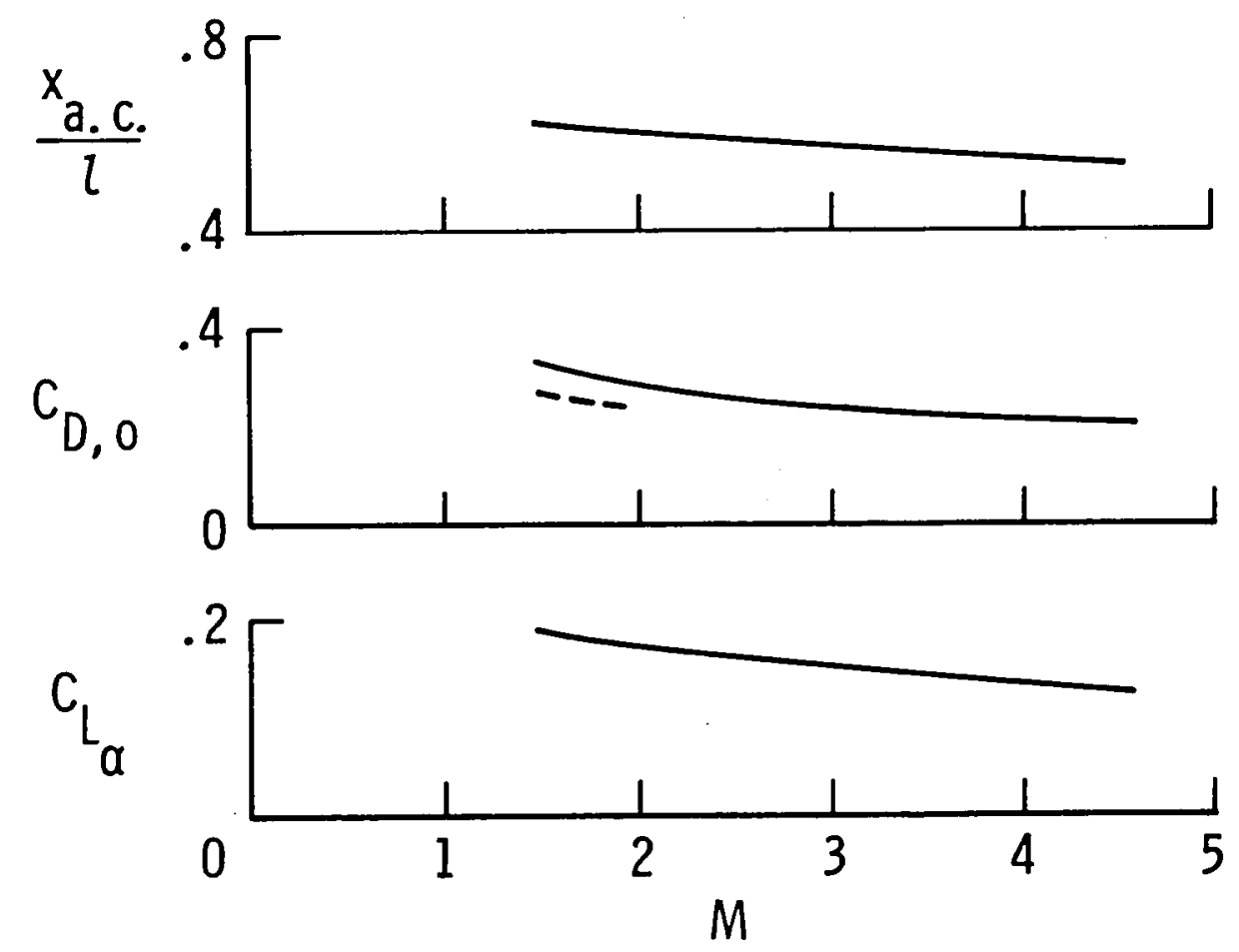

Figure 12. - Longitudinal summary, wing-body with tail control, $\phi=0^{\circ}$ and $45^{\circ}, \delta=0^{\circ}$. 


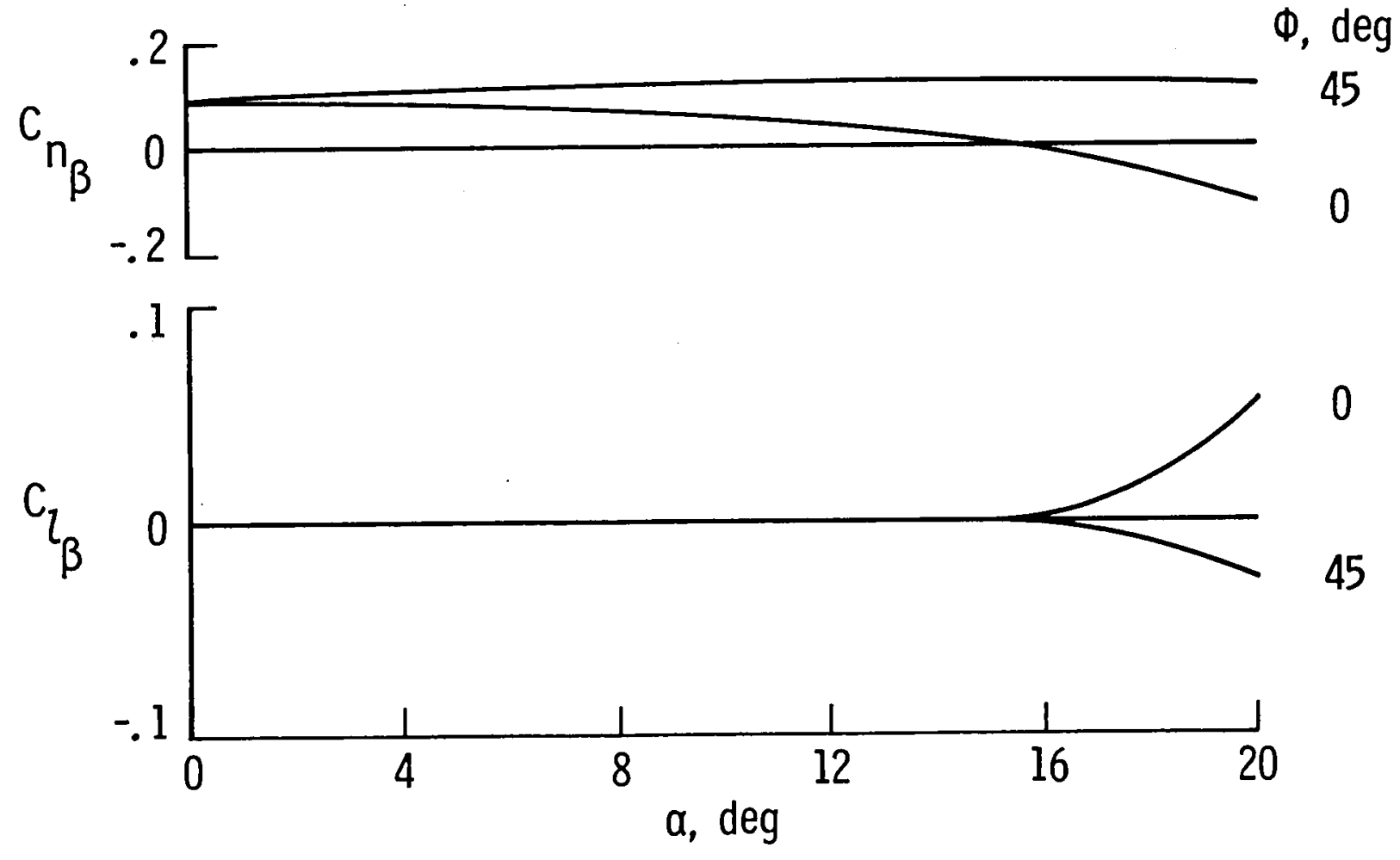

Figure 13. - Directional-lateral stability, wing-body with tail control, $M=1.9, \delta=0^{\circ}$, c.g. $=0.57$ l. 


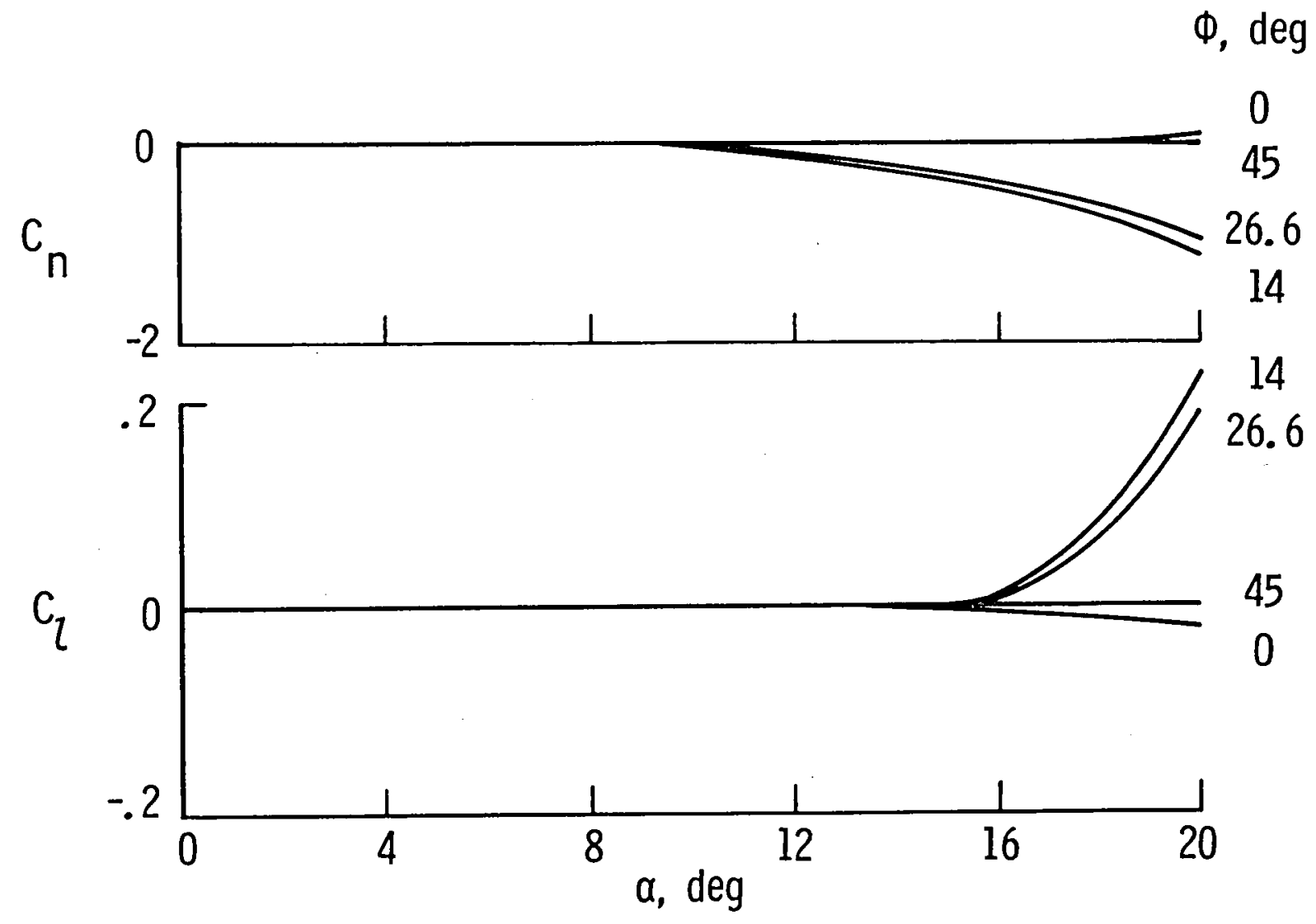

Figure 14.- Induced lateral characteristics, wing-body with tail control, $M=1.9, \delta=0^{\circ}$. 

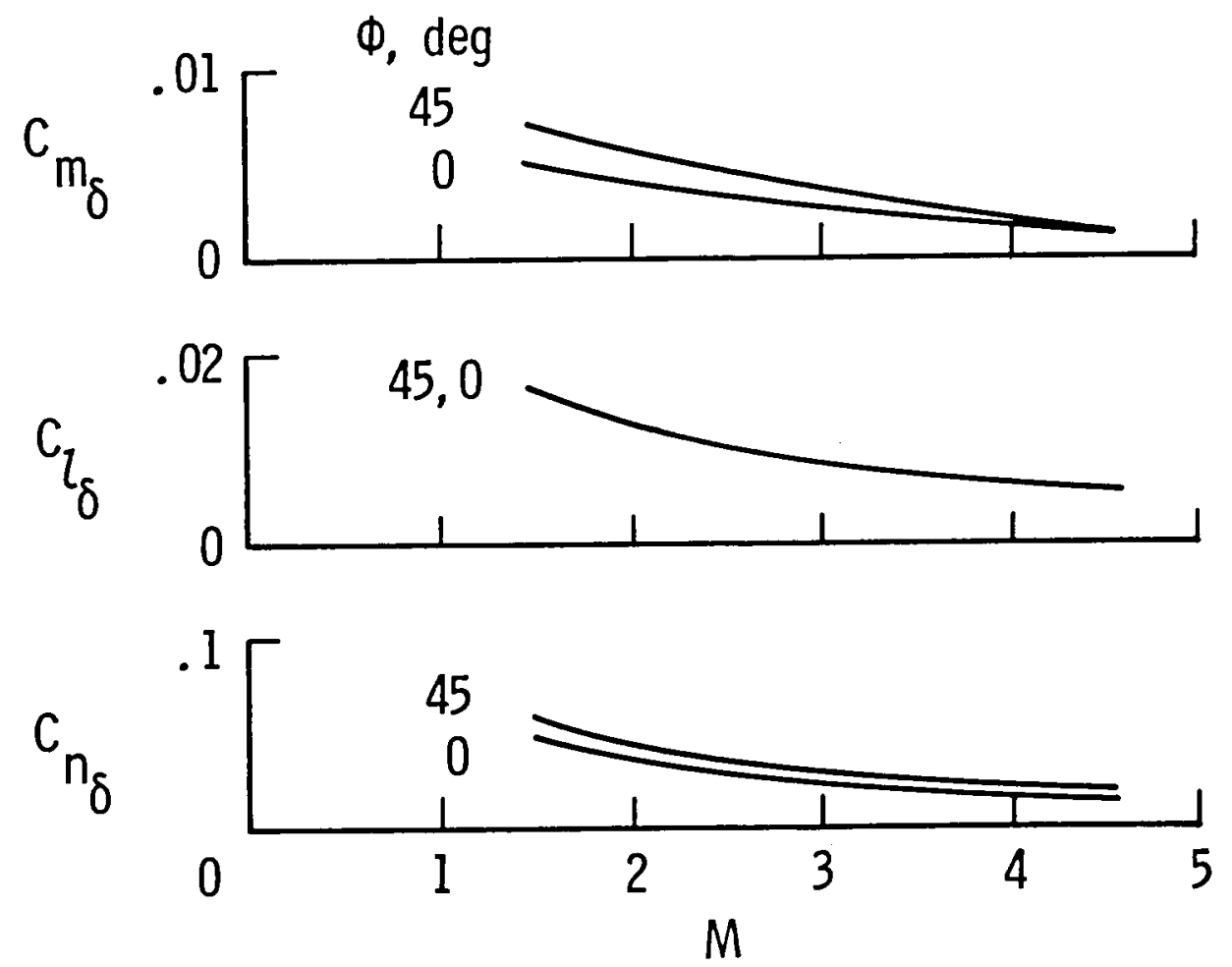

Figure 15.- Control summary, wing-body with tail control, c.g. $=0.57$ l 


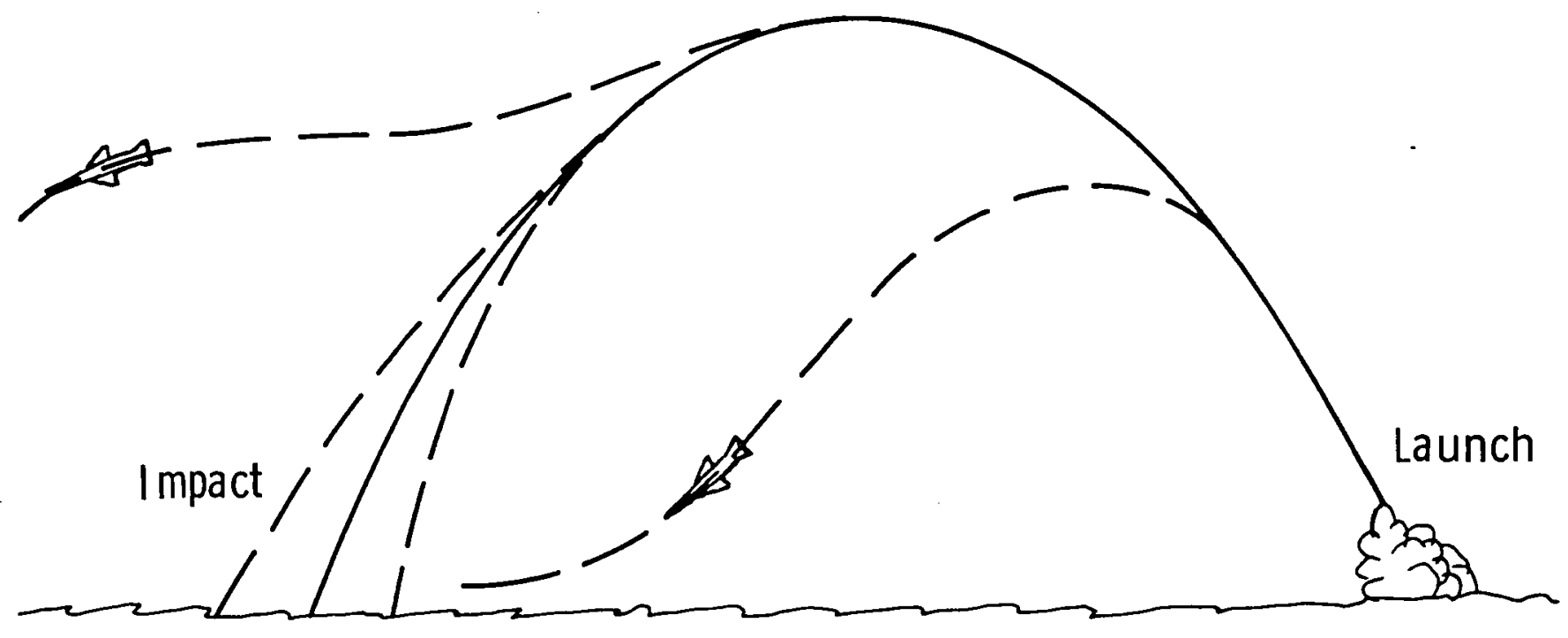

Figure 16. - Alternate trajectories. 


\begin{tabular}{|c|c|c|c|c|}
\hline $\begin{array}{l}\text { 1. Report No. } \\
\text { NASA TM-86334 }\end{array}$ & \multicolumn{2}{|c|}{ 2. Government Accession No } & \multicolumn{2}{|c|}{ 3. Recipient's Catalog No. } \\
\hline \multirow{2}{*}{\multicolumn{3}{|c|}{$\begin{array}{l}\text { 4. Title and Subtitle } \\
\text { THE AERODYNAMICS OF SOME GUIDED PROJECTILES }\end{array}$}} & \multicolumn{2}{|c|}{$\begin{array}{l}\text { 5. Repon Date } \\
\text { December } 1984\end{array}$} \\
\hline & & & \multicolumn{2}{|c|}{$\begin{array}{l}\text { 6. Pertorming Organization Code } \\
505-43-43-01\end{array}$} \\
\hline \multirow{2}{*}{\multicolumn{3}{|c|}{$\begin{array}{l}\text { 7. Author(s) } \\
\text { M. Leroy Spearman }\end{array}$}} & \multicolumn{2}{|c|}{ 8. Performing Organization Report No. } \\
\hline & & & & \\
\hline \multirow{3}{*}{\multicolumn{3}{|c|}{$\begin{array}{l}\text { 9. Performing Organization Name and Address } \\
\text { NASA Langley Research Center } \\
\text { Hampton, Virginia } 23665\end{array}$}} & \multicolumn{2}{|c|}{ 10. Work Unit No. } \\
\hline & & & \multicolumn{2}{|c|}{ 11. Contract or Grant No. } \\
\hline & & & \multirow{2}{*}{\multicolumn{2}{|c|}{$\begin{array}{l}\text { 13. Type of Repon and Period Covered } \\
\text { Technical Memorandum }\end{array}$}} \\
\hline \multirow{2}{*}{\multicolumn{3}{|c|}{$\begin{array}{l}\text { 12. Sponsoring Agency Name and Address } \\
\text { National Aeronautics and Space Administration } \\
\text { Washington, DC } 20546\end{array}$}} & & \\
\hline & & & \multicolumn{2}{|c|}{ 14. Sponsoring Agency Code } \\
\hline \multicolumn{5}{|c|}{$\begin{array}{l}\text { 15. Supplementary Notes } \\
\text { Colateral release with paper presented at the AIAA } 11 \text { th Atmospheric F1ight } \\
\text { Mechanics Conf., Seattle, WA, August } 21-23,1984 \text {. }\end{array}$} \\
\hline \multicolumn{5}{|c|}{$\begin{array}{l}\text { 16. Abstract } \\
\text { Some characteristic projectile shapes are considered with various added } \\
\text { components intended to provide lift, stability, and control. The intent of } \\
\text { the additions is to provide some means for altering the normal ballistic } \\
\text { flight path of a projectile for various purposes such as: achieving greater } \\
\text { accuracy at the impact point, selecting alternate impact points, extending } \\
\text { range, improved evasion, and so on. The configurations presented illustrate } \\
\text { the effects of a flare, wings, and tails for providing stability and lift, and } \\
\text { the effects of aft-tails, a close-coupled flap, and all-moving forward wings } \\
\text { for control. The relative merits of the various configurations, all of which } \\
\text { provided for flight path alterations, are discussed. }\end{array}$} \\
\hline \multicolumn{2}{|c|}{$\begin{array}{l}\text { 17. Key Words (Suggested by Author(s)) } \\
\qquad \begin{array}{l}\text { Projectiles } \\
\text { Missile configurations } \\
\text { Trajectories }\end{array}\end{array}$} & \multicolumn{3}{|c|}{$\begin{array}{l}\text { 18. Distribution Statement } \\
\text { Unclassified - Unlimited } \\
\text { Subject Category } 01\end{array}$} \\
\hline $\begin{array}{l}\text { 19. Security Classif. lol this reportl } \\
\text { Unclassified }\end{array}$ & $\begin{array}{l}\text { 20. Security } \\
\text { Un }\end{array}$ & & Pages & $\begin{array}{l}\text { 22. Price } \\
\text { A02 }\end{array}$ \\
\hline
\end{tabular}



$:$ 


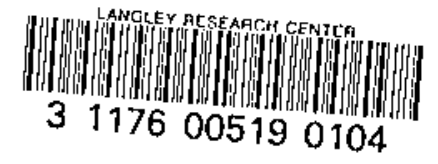

